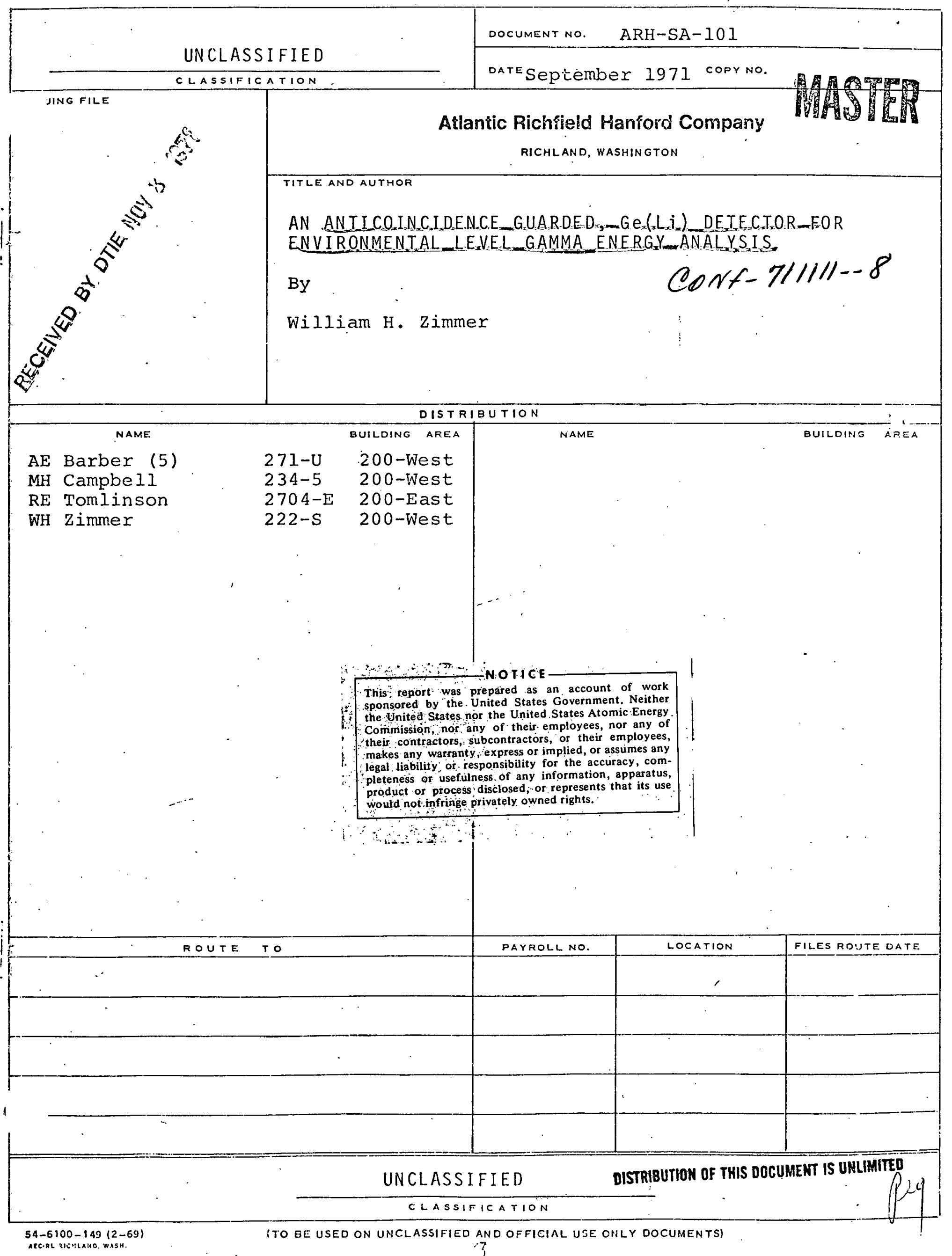




\section{DISCLAIMER}

This report was prepared as an account of work sponsored by an agency of the United States Government. Neither the United States Government nor any agency Thereof, nor any of their employees, makes any warranty, express or implied, or assumes any legal liability or responsibility for the accuracy, completeness, or usefulness of any information, apparatus, product, or process disclosed, or represents that its use would not infringe privately owned rights. Reference herein to any specific commercial product, process, or service by trade name, trademark, manufacturer, or otherwise does not necessarily constitute or imply its endorsement, recommendation, or favoring by the United States Government or any agency thereof. The views and opinions of authors expressed herein do not necessarily state or reflect those of the United States Government or any agency thereof. 


\section{DISCLAIMER}

Portions of this document may be illegible in electronic image products. Images are produced from the best available original document. 


\title{
AN ANTICOINCIDENCE GUARDED, Ge(Li) DETECTOR FOR ENVIRONMENTAL LEVEL GAMMA ENERGY ANALYSIS
}

By

\author{
William H. Zimmer \\ Separations Chemistry Laboratory \\ Research and Development \\ Chemical Processing Division
}

September 1971

\section{ATLANTIC RICHFIELD HANFORD COMPANY}

RICHLAND, WASHINGTON

To be presented at the

IEEE 1971 Nंuclear Science Symposium

Nuclear Instrumentation for Research and Development November 3-5, 1971

San Francisco, California

Operated for the Atomic Energy Commission by Atlantic Richfield Hanford Company under Contract \#AT(45-1)-2130 
TABLE OF CONTENTS

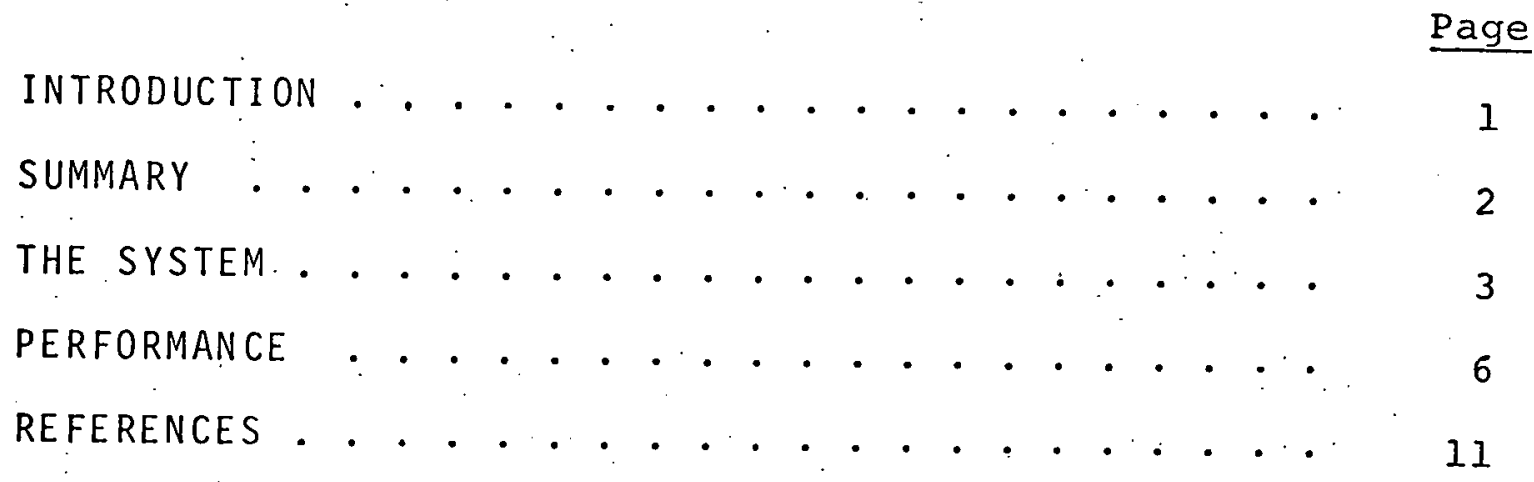




\section{ABSTRACT}

The environmental level gamma energy system developed at Atlantic Richfield Hanford Company laboratories consists of a single, large volume Ge(Li) detector with an NaI(TI) anticoincidence guard, all operating in a laminar flow "Clean: Room." A peak height to Compton edge ratio of better than 250:1, together with a reducing background, enables analysis of sample volumes from point sources to $700 \mathrm{cc}$. 


\section{AN ANTICOINCIDENCE GUARDED, Ge(Li) DETECTOR FOR ENVIRONMENTAL LEVEL GAMMA ENERGY ANALYSIS}

\section{INTRODUCTION}

In order to analyze samples that emit no more gamma activity than is encountered in normal background, it is necessary to enhance the counts to be analyzed and suppress those which interfere: The enhancement is achieved in this system by a large volume lithium drifted germanium [Ge(Li)] primary detector. The detector is large for efficiency and is $\mathrm{Ge}$ (Li) for its ability to resolve the recorded counts from each other and from the background.

Suppression of interference requires passive shielding for reduction of interference to the primary detector and a shielding or guard detector around the primaxy detector for active suppression. The guard detector is in anticoincidence to the primary detector; that is, any time there is a pulse recorded in the primary that has a coincident pulse recorded in the guard, both pulse records are cancelled. This limits the back'ground that is recorded by the primary since most of that activity must pass through the guard detector in order to reach the primary detector. It also limits the recording of emission absorption events which occur partly in the primary detector and escape, because the most probable escape route is to the surrounding guard detector. We have therefore arrived at an anticoincidence guarded, Ge(Li) detector for environmental level gamma energy analysis.

Once the detector system had been designed that will yield an acceptable level of sample count enhancement and interference suppression, it remained to develop methods of sample handling which would sustain and improve, the performance. 


\section{SUMMARY}

The Separations Chemistry Laboratory (SCI) of Atlantic Richfield Hanford Company (ARHCO) has three primary goals to fulfill in designing a 'Ge(Li) environmental level gamma analytical system:

- Samples with a liquid volume of $700 \mathrm{~cm}^{3}$ were to be gamma energy analyzed with better counting precision and accuracy than could the same sample in the existing system after concentration to $1 \mathrm{~cm}^{3}$. The system previously most sensitive was a $5 " x 5^{\prime \prime}$ NaI(Tl) well detector system, anticoincidence guarded by a plastic scintillator.

- Samples from a point source to $50 \mathrm{~cm}^{3}$ in volume were to be analyzed at picocurie activity levels with a peak to Compton edge ratio. of better than 200:1 for the $661.6 \mathrm{keV}$ peak of cesium-137.

- An initial low background was to be established and sample mounting and handling techniques developed which would not raise that background.

After 18 months of operation all of the initial goals have been. met and exceeded. The minimum detection limit for monoenergetic ${ }^{137} \mathrm{Cs}$ is $0.3 \mathrm{pCi} / \mathrm{ml}$ without the anticoincidence guard as opposed to $2.0 \mathrm{pCi} / \mathrm{ml}$ for a $1 \mathrm{milli}$.i.ter sample in the 5" $x$ 5", anticoincidence guarded, NaI(Tl) well detector system (for a one-hour analysis and accepting a precision of $\pm 20 \%$ at the $95 \%$ confidence level ${ }^{1,2}$ ).

A peak to Compton ratio of $220: 1$ and a detection limit of 1.8 picocuries per milliliter 1.2 for the $661.6 \mathrm{keV}$ peak of ${ }^{137} \mathrm{Cs}$ has been achieved using a $40 \mathrm{~cm}^{3}$ mount. Background has actually been reduced within the 18-month period of measurement. 


\section{THE SYSTEM}

The Separations Chemistry Laboratory of Atlantic Richfield Hanford Company is a research and development group chartered, in part, to develop gamma energy analytical systems for application in separations process support laboratories and in direct support of the separations processes by nonroutine analyses. This includes support analysis for waste management and environmental monitoring and control. We share an admirably located counting room with one of the process support laboratories and both groups are engaged in a great deal. of medium- to high-activity level sample analyses. It had been our experience that low background could be attained in this location but not maintained. Dust and lint carried low-level radioactive contamination into every cranny; and inevitably raised the background. Consequently, as much planning went into methods of retaining an acceptable background as went into the detector configuration that would fulfill our sensitivity requirements.

The location of the detector shield was chosen on the basis of low starting background, constant temperature, and a low traffic frequency. The entire area was then cleaned to the bare-bones structure. The floor was cleaned to the concrete, and new seamless vinyl flooring laid. The metal panel walls and ceiling were repainted and sealed. A laminar downflow clean room filter was then installed to provide a floor area of $6^{\prime} \times 8^{\prime}$, the area to be shared with a planchet counter.

From this time all personnel entering the clean room area were required to don non-linting coverings from heat to foot. Every lead brick was scraped and burnished before it was handed into the enclosure. Cadmium and copper grading were used throughout the interior of the shield to reduce the level of lead $x$-ray fluorescence recorded in the primary detector when used in the nonanticoincidence configuration. 
The primary detector system consists of a Nuclear Diode $88 \mathrm{cc}$, closed end, coaxial $\mathrm{Ge}(\mathrm{L} i)$ in a vertically down, chicken-feeder cryostat. The germanium ingot is a right cylinder, $41 \mathrm{~mm}$ in diam and $71 \mathrm{~mm}$ long. It has been drifted to a depth of $15 \mathrm{~mm}$, mounted in a magnesium cold finger frame, and surrounded for its full annular length by a thin internal heat shield. The cryostat cap and end window are made from 3" diam, $0.5 \mathrm{~mm}$ thick, low-activity aluminum.: The resulting Ge(Li) detector fulfilled our requirements of a large surface area, heat-shielded detector suitable for immersion and for a large-volume, high-sensitivity detector sui.table for anticoincidence analysis. The 17-liter dewar-cryostat assembly is enclosed by the shield and supported at three points which are not grounded to the shield. One of the three support points is a Stratham (trade name of Honeywell, Inc.) strain gauge which monitors the weight of the primary detector assembly. An alarm is triggered to sound from this monitor any time the liquid nitrogen level drops below a safe minimum or when a sample applies too much pressure on the cryostat cap.

The guard detector is a 9.5" diam by 12 " high NaI(TI) annulus detector. The annulus diameter is $3.5^{\prime \prime}$ and this is filled to a height of 3 " with a 3-7/16" diam, cylindrical, NaI(Tl) detector. Both the interior surface of the annulus and the cylindrical surface of the plug have a minimum thickness, sprayed reflector and aluminum can wall. The annulus is provided with six $2 "$ " multiplier phototubes and the plug with a single 3" tube. All have been provided with low-noise, nonphenolic bases ari magnetic shields. The guard detector is lowered for sample loading on a manually operated lift assembly, synchronized by chain-driven screws in regurgitating ball nuts.

The electronic block diagram is provided in Figure 1. Separate preamplifier power supplies are used since the primary and secondary preamplified signals are driven a distance of approximately 18 meters to the amplifiers and analyzer. 

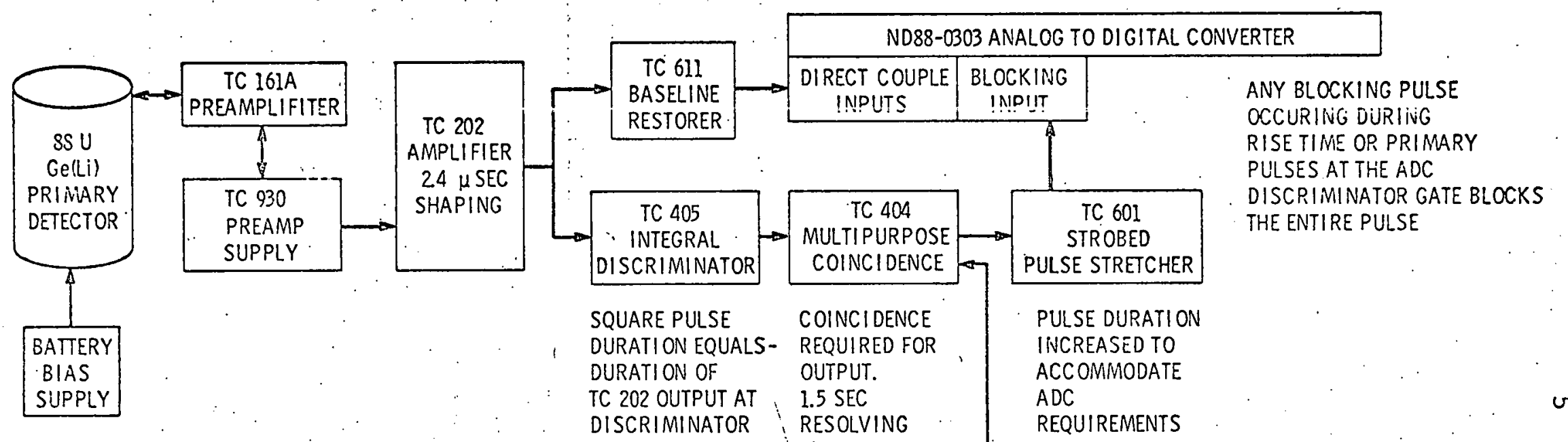

DISCRIMINATOR RESOLVING

REQUIREMENTS

$\cdot+\frac{1}{2}$

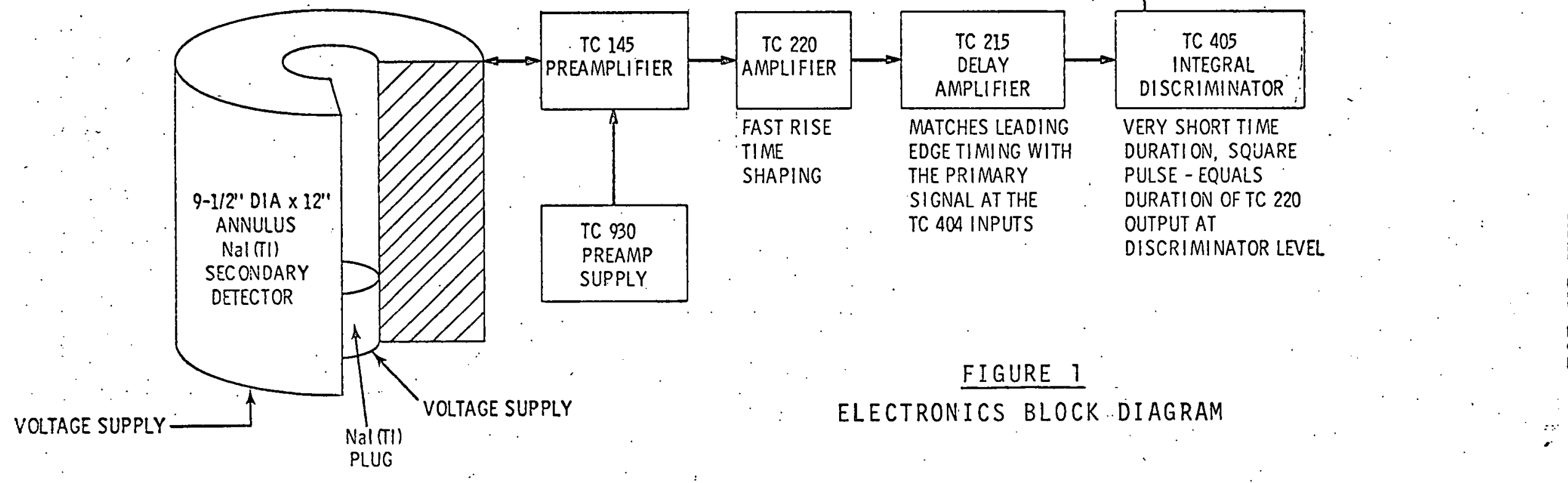


The primary detector was initially supplied with a Tennelec TC135 preamplifier. It has since been replaced by a TCl6lA with a $12 \%$ improvement in resolution and $10 \%$ improvement in peak to Compton edge ratios.

\section{PERFORMANCE}

Background spectrum in Figure 2 is for the primary detector alone, with no active background or Compton suppression. Figure 3 is the background spectrum for the system in the anticoincidence (AC) mode of operation. For energies higher than $300 \mathrm{keV}$, the background continuum for the anticoincidence mode is reduced by approximately 10-fold from the non-AC background, as expected. The significant factor is the absence of fission and irradiation product emission peaks. Despite all precautions, traces of these emissions were detectable immediately. after fabrication; in 18 months of operation they have decayed out of the background and no new emitter sources have been introduced. Only very long-lived natural emitters remain and the overall background has been reduced.

The continued low background level is due to the laminar flow clean room and the administrative procedures developed to keep it clean. All personnel entering this area must don plastic shoe coverings and disposable, non-linting paper coveralls and caps. All samples are prepared in clean preparation rooms operated under the same controls. Individually, all samples are sealed in non-linting counting containers. If. the samples are aqueous they are gelled using 2\% Kelzan (trade name of Kelco Company), a polysacchoride gum, to immobilize the sample and reduce the potential for spills. The 700-cc mounts use only $0.5 \%$ Kelzan which partially gels the sample, suspending any particulate matter but permitting the liquid to self-level in the counting configuration. Between the preparation laboratory and the counting facility, everything 


\section{FIGURE 2}

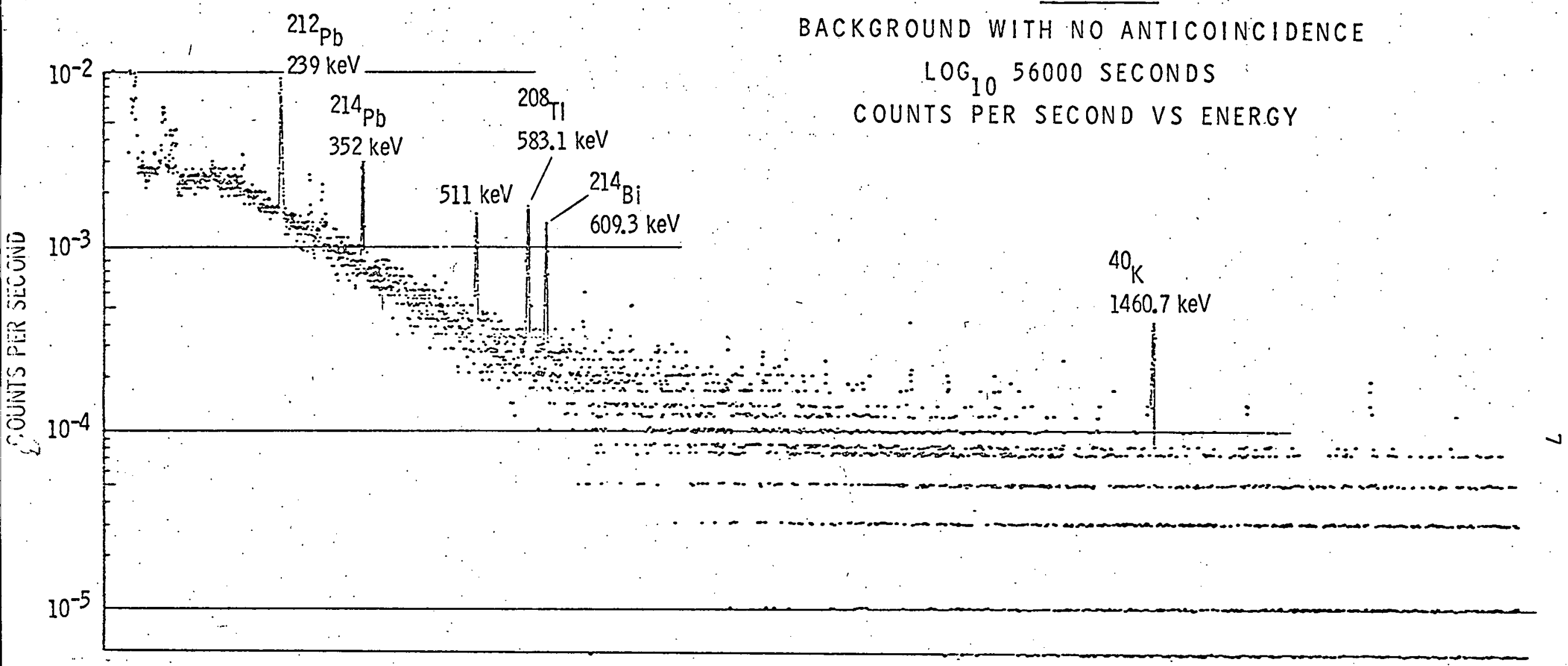


FIGURE 3

BACKGROUND WITH ANTICOINCIDENCE

${ }_{\text {LOG }}{ }_{10} 56000$ SECONDS

COUNTS PER SECOND VS ENERGY.

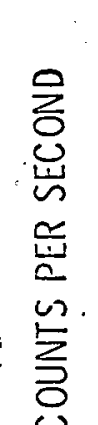

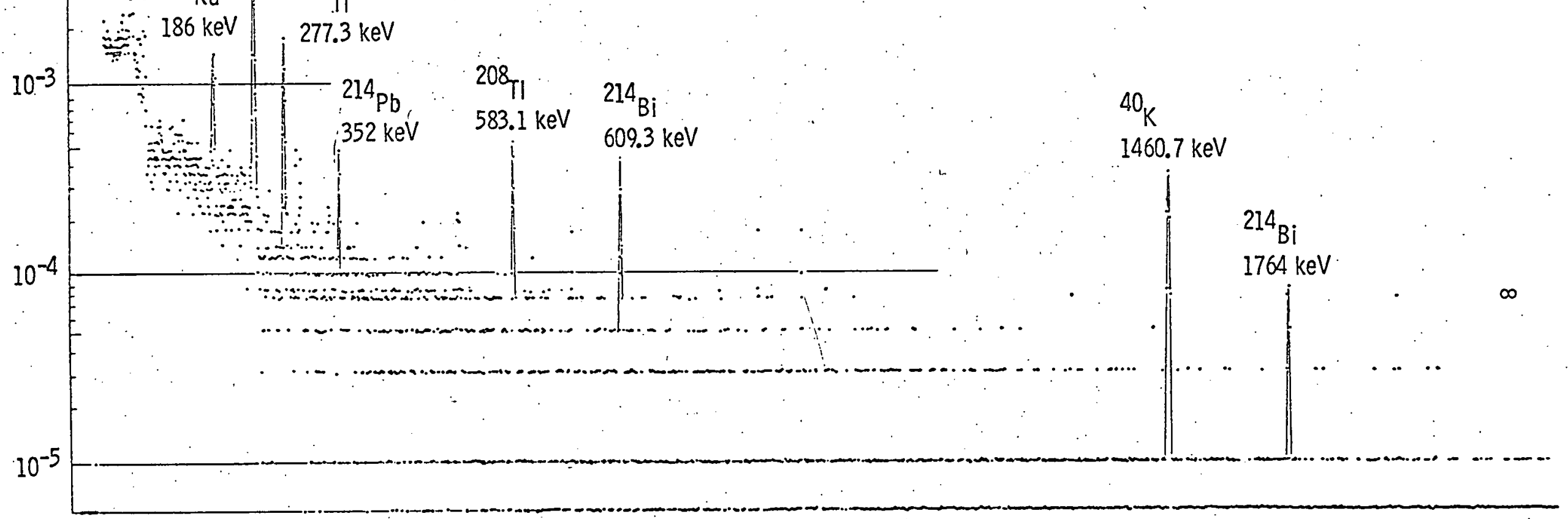


is further enclosed in plastic bags. All incoming samples are monitored using a $2 " \mathrm{x} 2 " \mathrm{NaI}(\mathrm{Tl})$ detector, $2 \mathrm{MHz} \mathrm{ADC}, 100$ channel analyzer. Any container recording more than $2 \%$ deadtime is analyzed in an alternate system.

Primary detector performance or performance without anticoincidence Compton or background suppression concerns only the 700-cc counting configuration. The sample is contained between two polyethylene bags and shaped by two polystyrene containers so that the primary detector is effectively immersed in the sample with a nominal 1" layer of sample at both the bottom and cylindrical sides of the cryostat cap. The system has a resolution of $2.52 \mathrm{keV}$ Full Width at Half Maximum (FWHM) for the $1332.4 \mathrm{keV}$ peak of ${ }^{6}{ }^{\circ} \mathrm{Co}$ and $2.19 \mathrm{keV}$ FWHM for the $661.6 \mathrm{keV}$ peak of ${ }^{13}{ }^{7} \mathrm{Cs}$. Peak to Compton edge ratio for the ${ }^{137} \mathrm{Cs}$ spectrum is $28.4: 1$. The efficiency of the primary compared with a $3^{\prime \prime} \times 3^{\prime \prime} \mathrm{NaI}$ (TI) at $25 \mathrm{~cm}$ from the closed end of the detector using the $1332.4 \mathrm{keV}$ peak of ${ }^{60} \mathrm{Co}$ is $10.2 \%$. The 700-cc counting configuration takes advantage of the surface area of the Ge(Li) detector in providing an optimum sensitivity for activity in environmental level activity in environmental level activity samples which do not respond quantitatively to concentration techniques. Absolute efficiency at the energy of the $661.6 \mathrm{keV}$ peak is $0.48 \%$.

Anticoincidence performance reduces the background to the spectrum in Figure 3. With a flat mount, 1 " in diameter, 3/16" from the window of the primary, the peak to compton edge ratio for the ${ }^{137} \mathrm{Cs}$ peak is improved from $34.8: 1$ to 275:1, an improvement by a factor of 7.9. Absolute efficiency at the energy of the $661.6 \mathrm{keV}$ peak is $1.37 \%$.

Most samples analyzed in detector systems such as that being described are of necessity bulk samples. Two configurations are used in this system--both 7/8" deep and, respectively, 2 and 2.5" in diameter. Both are also molded 
polystyrene boxes. The smaller has a volume of $40 \mathrm{~cm}^{3}$ (cc) and is primarily used for crushed basalt or whole well core sections. Specific gravity of the material is approximately three grams per $\mathrm{cm}^{3}$ and the peak to compton edge ratio is reduced to $220: 1$. Absolute efficiency at the ${ }^{137} \mathrm{Cs}$ peak is $0.76 \%$. With this configuration a significant contribution has been made toward mapping the basaltic flows underlying Hanford. Analyses for ${ }^{40} \mathrm{~K},{ }^{26} \mathrm{Ra}$ daughters, and ${ }^{228} \mathrm{Th}$ daughters are performed to a precision of 10 to $12 \%$ at the $95 \%$ confidence level in a four-hour counting period. The ${ }^{40} \mathrm{~K}$ values in particular have been used to identify and trace specific flows for miles. The ${ }^{40} \mathrm{~K}$ acts as a natural tracer to $\mathrm{K}_{2} \mathrm{O}$ content; which, in turn, has previously been reported as fingerprinting specific basaltic flows. The gamma energy analyses have confirmed well gamma logs and destructive trace element analyses in well cores. ${ }^{3}$

The 2.5" diameter mount contains $65 \mathrm{cc}$ of sample, usually in the one gram per $c c$ density range. Absolute efficiency at the ${ }^{1.37} \mathrm{Cs}$ peak is $0.56 \%$ and the peak to compton edge ratio is 195:1. The added volume of the mount justifies the poorer performance.

Cesium-137 has been used throughout the presentation as the performance reference. It is realized that sample spectra will normally be quite complex, but interference of emitter peaks in this:system have been negligible. Normal efficiency curves are calibrated for each sample configuration and the $661.6 \mathrm{keV}$ points served only as a convenient point of reference to show differences in curves which are basically of the same family. 


\section{REFERENCES}

1. J. A. Cooper, Factors Determining the Ultimate Detection Sensitivity of Ge(Li) Gamma-Ray Spectrometers, USAEC Report BNWL-SA-2940, January 23, 1970.

2. W. H. Zimmer, A Systematic Peak Reduction Method for Semiconductor Detector Spectra, USAEC Report ARH-1877, January 15, 1971.

3. D. J. Brown, Preliminary Hanford Stratographic Framework-. Interim Report, USAEC Report ARH-2170, JuIY 29, 1971. 